\title{
Comparative study of Speed Estimators Applied to Wind Turbine with Harmonic Distortion in both the Currents and the Voltages
}

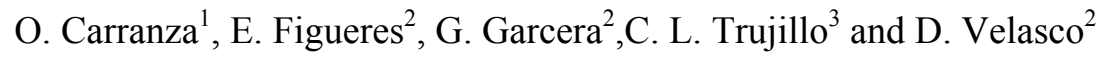 \\ ${ }^{1}$ Escuela Superior de Cómputo, Instituto Politécnica Nacional \\ Av. Juan de Dios Bátiz S/N, 07738, D. F. (Mexico) \\ Phone number:+52 5557296000 ext 52022, e-mail: ocarranzac@ipn.mx
}

\begin{abstract}
${ }^{2}$ Grupo de Sistemas Electrónicos Industriales del Departamento de Ingeniería Electrónica, Universidad Politécnica de Valencia, Camino de Vera S/N, 7F, 46022, Valencia (Spain)

Phone number:+34 963879606, e-mail: ggarcera@eln.upv.es, efiguere@eln.upv.es, davede@posgrado.upv.es
\end{abstract}

\author{
${ }^{3}$ Departamento de Ingeniería Electrónica, Universidad Distrital Francisco José de Caldas \\ Carrera 7 No. 40-53 Piso 5, Bogotá, (Colombia) \\ Phone/Fax number:+57 13239300/2506, e-mail: cltrujillo@udistrital.edu.co
}

\begin{abstract}
This paper presents a comparative study of different speed estimators to implement a sensorless speed control loop in a wind generation system with a Three-phase boost rectifier operating in discontinuous conduction mode. For implementation of the speed estimators, the compared techniques start from the measurement of electrical quantities like currents and voltages, which are highly distorted because of the components at the switching frequency of the boost rectifier and also the low frequency harmonics at multiples of the generator fundamental frequency. It is shown the linear Kalman filter estimator is appropriate for this application because of its fast response time and low error obtained.
\end{abstract}

\section{Key words}

"Sensorless", "Wind Generator System", "PLL", "Extender Kalman Filter", "Linear Kalman Filter"

\section{Introduction}

Currently, Wind Generator System (WGS) have a great interest for power inject on to the grid. This work is based on low power WSG based on Permanent Magnetic Synchronous Generator (PMSG) [1]. The WGS operates at variable speed, so that both amplitude and frequency of the generator output voltage varies in a certain range, following the wind speed. Therefore, these variations in the voltage are applied to the power converter.

For this application the power converter is a Three-Phase Boost Rectifier operated in Discontinuous Conduction Mode (DCM) with Peak Current Mode Control (PCC) [2]. The rectifier is connected to a power inverter, which injects the energy to the grid. The control system of the rectifier needs to know the generator speed, for closing the speed control loop. There are shafts mounted electromechanical speed sensors (resolvers, encoders or
Hall-effect sensors). However, the use of these sensors increases the complexity, weight and cost of the system. Due to the fact that both the voltages and currents of the PMSG depend on its mechanical speed, the speed can be obtained through the measurement of the electric quantities, eliminating the need for mechanical sensors. This technique is known as sensorless speed control. Fig. 1 shows the scheme of the Boost Rectifier with speed estimation.

In this work, the performance of several speed estimation techniques is studied: Speed estimation using a synchronous reference frame Phase Locked Loop, speed estimation using the Rectifier currents and voltages, Speed estimation using Extended Kalman Filter and speed estimation using the Linear Kalman Filter.

The problem in developing estimators is that both the PMSG currents and the voltages contain harmonic of its fundamental frequency and components at the switching frequency. They have different values depending on the generator speed, as it is shown in Fig. 2.

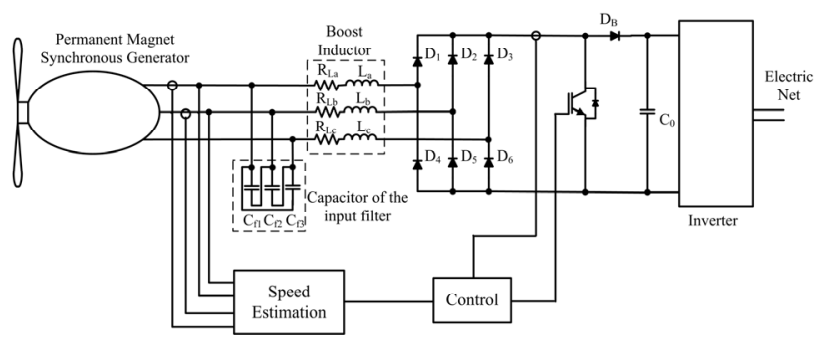

Fig. 1. Boost Rectifier with Speed Estimation 

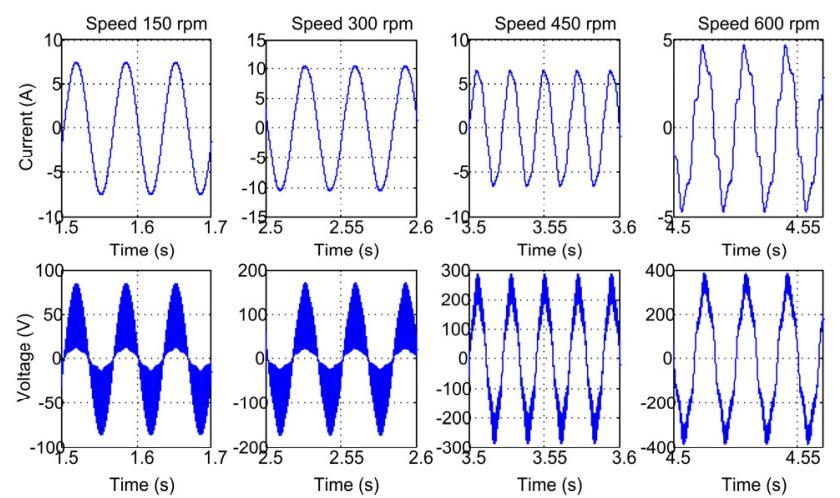

Fig. 2. Current and Voltage in one on the generator phase.

\section{Speed Estimation Using the Phase Locked Loop}

The Speed estimation using Phase Locked Loop (PLL) based on the synchronous reference frame [3]-[4] follows the scheme shown by Fig. 3. The three-phase quantities are translated to the $d q$ synchronous reference frame by using Park's transformation. The angular position of this $d q$ reference frame is controlled by a feedback loop which regulated the q component to be zero.

The loop gain to analyze the PLL stability is determined by:

$$
T_{P L L}(s)=V_{d} \cdot P I \cdot \frac{1}{S}
$$

$\mathrm{V}_{\mathrm{d}}$ is the magnitude of the component $d$ in the synchronous reference frame and PI is a simple proportional-integral controller. The generator speed range is between 150 and $600 \mathrm{rpm}$, in the considered application, so that the compensator PI is designed to stabilize the loop gain, $\mathrm{T}_{\mathrm{PLL}}(\mathrm{s})$, in the whole range of PMSG speed with a phase margin higher than $50^{\circ}$ and a cutoff frequency that should be less than half of the actual generator frequency (varying from $15 \mathrm{~Hz}$ to 60 $\mathrm{Hz}$ ). The parameters if the PI regulator are $\mathrm{K}_{\mathrm{p}}=70$ and $\mathrm{K}_{\mathrm{i}}=4200$.

\section{Speed Estimation Using the Currents and Voltage in the Rectifier}

The speed estimation using the currents and voltages in the Rectifier [5] follows the scheme shown by Fig. 4. Starting from [5], it may be shown that the frequency at the PMSG output voltages can be expressed following (2)

$$
f=\frac{\frac{\pi V_{\text {rect }}}{3}+\left(R_{g a}+R_{L a}\right) I_{\text {rect }}}{2 \pi\left(\frac{2 \sqrt{2} K_{\text {fem }}}{P}-\left(L_{g a}+L_{a}\right) I_{\text {rect }}\right)}
$$

$\mathrm{I}_{\text {rect }}$ and $\mathrm{Vr}_{\text {ect }}$ are the current and the voltage at the output rectifier, respectively. $\mathrm{K}_{\mathrm{fem}}$ is the electromotive force constant, $\mathrm{P}$ is number of poles, $\mathrm{R}_{\mathrm{ga}}$ and $\mathrm{L}_{\mathrm{ga}}$ are the resistance and inductance of one phase of the generator and $\mathrm{L}_{\mathrm{a}}$ and $\mathrm{R}_{\mathrm{La}}$ are the per phase Boost Inductor and resistance.

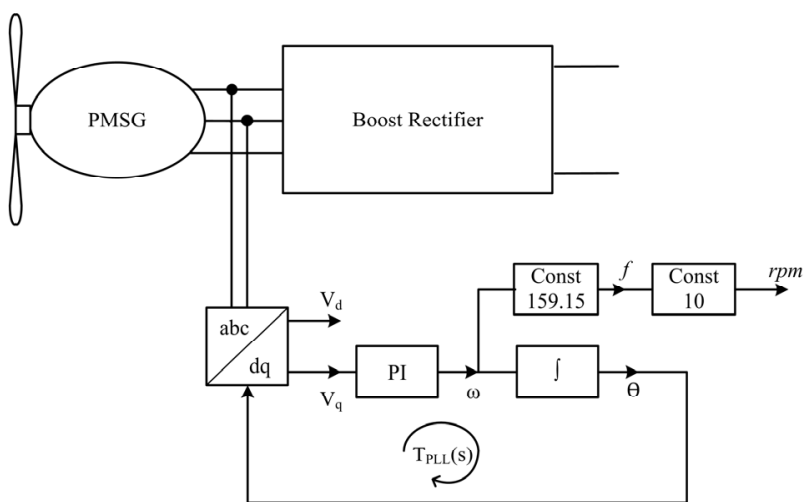

Fig. 3. Speed estimation using Phase Locked Loop

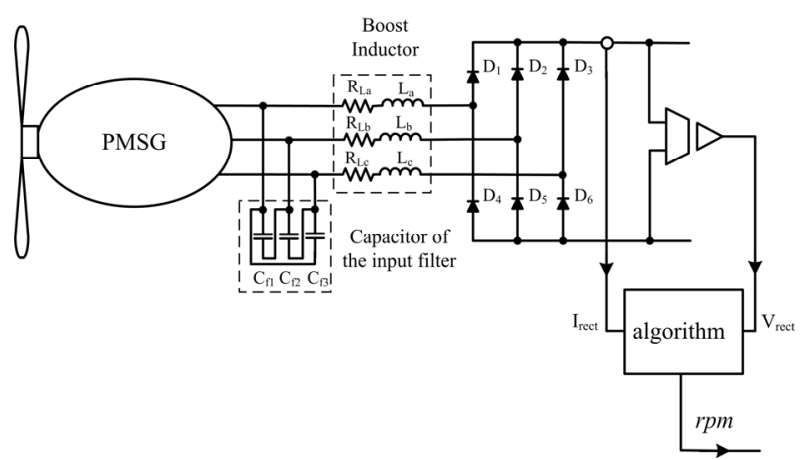

Fig. 4. Speed Estimation using the currents and the voltages in the Boost Rectifier.

The main inconvenience of this technique is that it depends on the characteristics of the boost rectifier and of the generator, which can change because of the components tolerance and degrading, producing estimation errors at long time. By other side the advantage is that it don't requires additional sensors, because needed are used by the control loop.

\section{Speed Estimation Using Extended Kalman Filter}

The Extended Kalman Filter (EKF) has been extensively used in Speed and position estimation of permanent magnet synchronous motors [6]-[7] and wind generators [8].

\section{A. Extended Kalman Filter.}

The discrete state formulation of the EKF [9] is defined by

$$
\begin{gathered}
x(k+1)=A_{k} x(k)+B_{k} u(k)+\sigma(k) \\
y(k)=C_{k} x(k)+\mu(k)
\end{gathered}
$$

$x$ is the estimated signal vector, $u$ is the deterministic input vector and $y$ is the output vector. $\sigma(\mathrm{t})$ and $\mu(\mathrm{t})$ represent the process and measurement zero-mean Gaussian noises, with $\mathrm{Q}$ and $\mathrm{R}$ that they are the covariance matrixes of the $\sigma(\mathrm{t})$ and $\mu(\mathrm{t})$. The noises are independent from the system state $x$, There also exists a covariance matrix $(\mathrm{P})$ of the estimation error that is used.

The EKF algorithm sets two steps: estimation and correction. The first step sets a prediction of state 
estimation $(x 1)$ and the covariance matrix $(P 1)$. This is realized by the following recursive relations:

$$
\begin{gathered}
x 1(k+1)=A_{k} \hat{x}(k)+B_{k} u(k) \\
P 1(k+1)=F(k+1) \hat{P}(k) F^{T}(k+1)+Q \\
F(k+1)=\frac{\partial\left[A_{k} \hat{x}(k)+B_{k} u(k)\right]}{\partial x}
\end{gathered}
$$

The second step corrects the prediction of the state estimation and the covariance matrix of the estimation, using a feedback of the measured quantities; this is realized by the following recursive relations:

$$
\begin{gathered}
\hat{x}(k+1)=x 1(k+1)+K(k+1) \\
\cdot[y(k+1) \\
\left.-C_{k}(k+1) x 1(k+1)\right] \\
\hat{P}(k+1)=P 1(k+1) \\
-K(k+1) H(k+1) P(k+1)
\end{gathered}
$$

Where $K(k+1)$ is the gain matrix of the filter and following (9).

$$
\begin{aligned}
K(k+1)= & P(k+1) H^{T}(k+1) \\
\cdot & \cdot\left[H(k+1) P(k+1) H^{T}(k+1)+R\right]^{-1}
\end{aligned}
$$

And $H(k+1)$ is determined by

$$
H(k+1)=\frac{\partial\left[C_{k} x(k)\right]}{\partial x}
$$

In this application, the EKF can apply by means of two forms: choosing the electromotive force in the PMSG, which is required to know PMSG model or using only the output voltages of the generator.

\section{B. Permanent Magnet Synchronous Generator Model.}

The equivalent circuit of the permanent magnet synchronous generator [10] is shown in Fig. 5.

Where $\mathrm{L}_{\mathrm{ga}}=\mathrm{L}_{\mathrm{gb}}=\mathrm{L}_{\mathrm{gc}}$ are the inductances of one phase, $\mathrm{R}_{\mathrm{Lga}}=\mathrm{R}_{\mathrm{Lgb}}=\mathrm{R}_{\mathrm{Lgc}}$ are the resistance in series of one phase, $V_{a}, V_{b} y_{c}$ are the generator output voltages and $e_{a}, a_{b} \mathrm{e} \mathrm{e}_{c}$ are electromotive forces that are expressed by (11)

$$
\begin{gathered}
e_{a}=K \omega_{e} \sin \left(\omega_{e} t\right) \\
e_{b}=K \omega_{e} \sin \left(\omega_{e} t-\frac{2 \pi}{3}\right) \\
e_{c}=K \omega_{e} \sin \left(\omega_{e} t+\frac{2 \pi}{3}\right)
\end{gathered}
$$

Where $\mathrm{K}$ is constant of the electromotive force and $\omega_{\mathrm{e}}$ is the electric angular frequency. The PMSG model can be expressed in the state space, as it is shown by (12).

$$
\left[\begin{array}{l}
V_{a} \\
V_{b} \\
V_{c}
\end{array}\right]=-R_{s}\left[\begin{array}{l}
i_{a} \\
i_{b} \\
i_{c}
\end{array}\right]-L_{s} \frac{d}{d t}\left[\begin{array}{l}
i_{a} \\
i_{b} \\
i_{c}
\end{array}\right]+\left[\begin{array}{l}
e_{a} \\
e_{b} \\
e_{c}
\end{array}\right]
$$

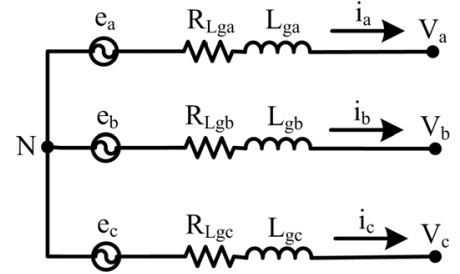

Fig. 5. The equivalent circuit of the permanent magnet synchronous generator.

However, in the estimator using EKF, the PMSG model is expressed in a synchronous reference frame, as shown by Fig. 6 .

$\mathrm{R}$ are the resistances in serie in each phase, $\mathrm{L}$ are the inductances in each phase, $\mathrm{V}_{\mathrm{d}}$ and $\mathrm{V}_{\mathrm{q}}$ are the output voltages in $d q$ frame, and $\mathrm{i}_{\mathrm{d}}$ and $\mathrm{i}_{\mathrm{q}}$ are the currents in the generator in $d q$ frame. The state space equations of the PMSG in the $d q$ synchronous reference frame are shown by (13).

$$
\begin{gathered}
V_{d}=-R i_{d}+L \omega_{e} i_{q}-L \omega_{e} i_{d} \\
V_{q}=-R i_{q}-L \omega_{e} i_{d}-L \omega_{e} i_{q}-\sqrt{\frac{3}{2}} K \omega_{e}
\end{gathered}
$$

\section{Estimation using Electromotive Force.}

The speed estimator using the electromotive force is shown in Fig. 7.

By comparing (13) and (3), it results (14).

$$
x=\left[\begin{array}{c}
i_{d} \\
i_{q} \\
\omega_{e} \\
\theta
\end{array}\right], \quad y=\left[\begin{array}{l}
i_{\alpha} \\
i_{\beta}
\end{array}\right], \quad u=\left[\begin{array}{l}
v_{\alpha} \\
v_{\beta}
\end{array}\right]
$$

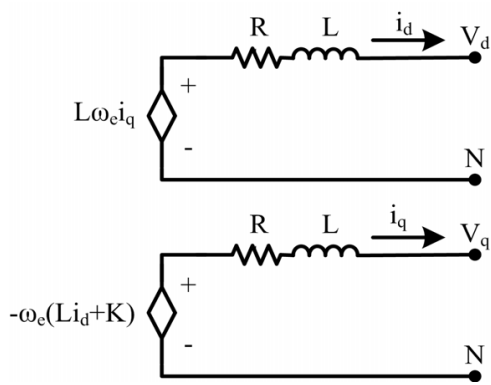

Fig. 6. The equivalent circuit of the PMSG in synchronous reference frame.

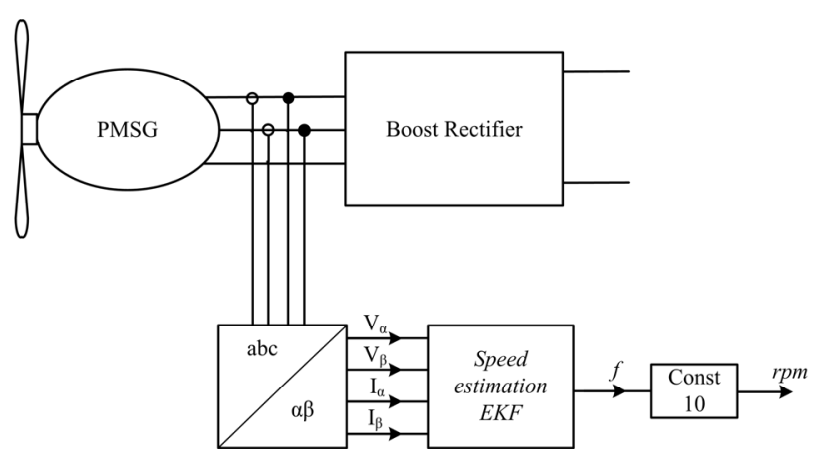

Fig. 7. Speed estimator EKF using electromotive force 
where $y$ and $u$ are the output and the measurement signals, respectively, in the stationary reference frame.

The discrete matrixes of the system are expressed by (15). Note that they depend on the sampling time $\left(T_{s}\right)$.

$$
\begin{gathered}
A_{k}=\left[\begin{array}{cccc}
1-\frac{T_{s} R}{L} & \omega_{e} T_{s} & 0 & 0 \\
-\omega_{e} T_{s} & 1-\frac{R T_{s}}{L} & -\sqrt{\frac{3}{2}} K \omega_{e} & 0 \\
0 & 0 & 1 & 0 \\
0 & 0 & T_{s} & 1
\end{array}\right] \\
B_{k}=\left[\begin{array}{ccc}
-\frac{T_{s} \cos \theta}{L} & -\frac{T_{s} \sin \theta}{L} \\
\frac{T_{s} \sin \theta}{L} & -\frac{T_{s} \cos \theta}{L} \\
0 & 0 \\
0 & 0
\end{array}\right] \\
C_{k}=\left[\begin{array}{cccc}
\cos \theta & -\sin \theta & 0 & 0 \\
\sin \theta & \cos \theta & 0 & 0
\end{array}\right]
\end{gathered}
$$

In this work, the covariance matrixes $\mathrm{Q}$ and $\mathrm{R}$ are chosen by a trial and error procedure to get the best tradeoff between filter stability and convergence time. The chosen values of $Q$ and $R$ are:

$$
Q=\left[\begin{array}{cccc}
0.5 & 0 & 0 & 0 \\
0 & 0.5 & 0 & 0 \\
0 & 0 & 2 & 0 \\
0 & 0 & 0 & 0.01
\end{array}\right] \text { and } R=\left[\begin{array}{ll}
1 & 0 \\
0 & 1
\end{array}\right]
$$

\section{Estimation using output voltages.}

In the speed estimator using the output voltages of the PMSG, the values of $x, u$ and $y$ are given by (16). However, $y$ and $u$ are measurement and output signals in the stationary reference frame.

$$
x=\left[\begin{array}{c}
v_{d} \\
v_{q} \\
\omega_{e} \\
\theta
\end{array}\right], \quad y=u=\left[\begin{array}{l}
v_{\alpha} \\
v_{\beta}
\end{array}\right]
$$

The discrete matrixes of the system are expressed by (17). Again, they depend on the sampling time $\left(\mathrm{T}_{\mathrm{s}}\right)$.

$$
\begin{gathered}
A_{k}=\left[\begin{array}{cccc}
1 & 0 & 0 & 0 \\
0 & 1 & 0 & 0 \\
0 & 0 & 1 & 0 \\
0 & 0 & T_{s} & 1
\end{array}\right], \quad B_{k}=\left[\begin{array}{cc}
T_{s} \cos \theta & T_{s} \sin \theta \\
-T_{S} \sin \theta & T_{s} \cos \theta \\
0 & 0 \\
0 & 0
\end{array}\right] \\
C_{k}=\left[\begin{array}{cccc}
\cos \theta & -\sin \theta & 0 & 0 \\
\sin \theta & \cos \theta & 0 & 0
\end{array}\right]
\end{gathered}
$$

The values of $\mathrm{Q}$ and $\mathrm{R}$ in this case are:

$$
Q=\left[\begin{array}{cccc}
0.5 & 0 & 0 & 0 \\
0 & 0.5 & 0 & 0 \\
0 & 0 & 2 & 0 \\
0 & 0 & 0 & 0.01
\end{array}\right] \text { and } R=\left[\begin{array}{ll}
1 & 0 \\
0 & 1
\end{array}\right]
$$

\section{Speed Estimation Using The Linear Kalman Filter}

The speed estimation using EKF can be simplified if the filter structure is known [11]-[13]. This estimation is called Linear Kalman Filter (LKF). Instead of calculating a variable gain matrix $K$, (9), which requires a high computational calculation, a constant gain matrix $\mathrm{K}_{\mathrm{s}}$ is obtained by means of the reduced system.

Considering the model for rotor position $\theta(k)$ and angular frequency $\omega_{e}(k)$ of the PMSG:

$$
\begin{gathered}
\theta(k+1)=\theta(k)+T_{s} \omega_{e}(k) \\
\omega_{e}(k+1)=\omega_{e}(k)+\dot{\sigma}(k) \\
\dot{\sigma}(k+1)=\dot{\sigma}(k)+\sigma(k)
\end{gathered}
$$

Where $\sigma(k)$ is the noise. The state vector is defined as (19):

$$
x=\left[\begin{array}{c}
\theta \\
\omega_{e} \\
\dot{\sigma}
\end{array}\right]
$$

For the analysis of the simplified estimator, the output variables are the output voltages of the PMSG in the stationary reference frame.

$$
\left[\begin{array}{l}
y_{1}(k) \\
y_{2}(k)
\end{array}\right]=\left[\begin{array}{l}
V_{\alpha} \\
V_{\beta}
\end{array}\right]
$$

The LKF estimator extracts the speed information from the fundamental component of the output voltages of the PMSG, while other harmonic components are considered as measurement noise, which is filtered out. This is beneficial in this application because the output voltages contain switching frequency components. The output variables are expressed in normalized form as

$$
\left[\begin{array}{l}
y_{1}(k) \\
y_{2}(k)
\end{array}\right]=\left[\begin{array}{l}
\cos \theta(k) \\
\sin \theta(k)
\end{array}\right]+\left[\begin{array}{l}
\mu_{1}(k) \\
\mu_{2}(k)
\end{array}\right]
$$

Where $\mu_{1}$ y $\mu_{2}$ are the switching noise and high-order low frequency harmonics, respectively. Considering the state space (18), the state vector (19) and the input $\mathrm{u}(\mathrm{k})=0$ in (3), it is obtained:

$$
\begin{gathered}
x(k+1)=A_{s} x(k)+G_{s} \sigma(k) \\
y(k)=C_{s} x(k)+\mu(k)
\end{gathered}
$$

Where the matrixes are:

$$
\begin{gathered}
A_{s}=\left[\begin{array}{ccc}
1 & T_{s} & 0 \\
0 & 1 & 1 \\
0 & 0 & 1
\end{array}\right] \text { and } G_{s}=\left[\begin{array}{lll}
0 & 0 & 0 \\
0 & 0 & 0 \\
0 & 0 & 1
\end{array}\right] \\
C_{s} x(k)=\left[\begin{array}{l}
\cos \theta(k) \\
\sin \theta(k)
\end{array}\right]
\end{gathered}
$$

Applying (10) to (24), it results: 


$$
H(k+1)=\frac{\partial C_{s} x(k)}{\partial x}=\left[\begin{array}{ccc}
-\sin \theta(k) & 0 & 0 \\
\cos \theta(k) & 0 & 0
\end{array}\right]
$$

However, to simplify $H(k+1)$, the $d q$ transformation matrix (T) can be used, following (26) and (27)

$$
\begin{gathered}
T=\left[\begin{array}{cc}
\cos \theta & -\sin \theta \\
\sin \theta & \cos \theta
\end{array}\right] \\
H(k+1)=\left[\begin{array}{cc}
\cos \theta & \sin \theta \\
-\sin \theta & \cos \theta
\end{array}\right]^{T}\left[\begin{array}{lll}
0 & 0 & 0 \\
1 & 0 & 0
\end{array}\right]
\end{gathered}
$$

where

$$
H_{S}=\left[\begin{array}{lll}
0 & 0 & 0 \\
1 & 0 & 0
\end{array}\right]
$$

Applying (26) to (9), it is obtained the simplified filter gain, following (29)

$$
K(k+1)=\left[\begin{array}{ll}
0 & K_{s 1} \\
0 & K_{s 2} \\
0 & K_{s 3}
\end{array}\right]\left[\begin{array}{cc}
\cos \theta(k) & -\sin \theta(k) \\
\sin \theta(k) & \cos \theta(k)
\end{array}\right]
$$

Where $K_{s 1}, K_{s 2}$ y $K_{s 3}$ are LKF gain and they are precalculated using the Matlab DLQE (A,G,C,Q,R) command [14], where the input variables are $\mathrm{A}=\mathrm{As}$, $\mathrm{G}=\mathrm{R}=\mathrm{Gs}, \mathrm{C}=\mathrm{Cs}$ and

$$
Q=\lambda\left[\begin{array}{ll}
0 & 0 \\
1 & 0
\end{array}\right]
$$

Where $\lambda$ allows to adjust the noise rejection ability and it is chosen by trial and error.

Starting from (7), it is obtained the estimation error; it is expressed by (31)

$$
\begin{gathered}
K(k+1) \cdot\left[y(k+1)-C_{s} x(k)\right]= \\
{\left[y_{2}(k) \cos \theta(k)-y_{1}(k) \sin \theta(k)\right]\left[\begin{array}{l}
K_{s 1} \\
K_{s 2} \\
K_{s 3}
\end{array}\right]}
\end{gathered}
$$

Finally, the LKF equations are expressed by

$$
\begin{gathered}
\varepsilon(k)=V_{\beta}(k) \cos \theta(k)-V_{\alpha}(k) \sin \theta(k) \\
\theta(k+1)=\theta(k)+T_{s} \omega_{e}(k)+K_{s 1} \varepsilon(k) \\
\omega_{e}(k+1)=\omega_{e}(k)+\sigma(k)+K_{s 2} \varepsilon(k) \\
\sigma(k+1)=\sigma(k)+K_{s 3} \varepsilon(k)
\end{gathered}
$$

For this application, $\lambda=5 \times 10^{6}, \quad K_{s 1}=0.0032896$, $K_{s 2}=0.54221$ and $K_{s 3}=0.00044647$. The LKF gains are independent of the PMSG parameters and could be used with a different PMSG. Another advantage is that only the output voltages of the PMSG are needed to be measured, reducing the cost of the sensors in the system. Fig. 8 shows the scheme of the speed estimator using LKF.

\section{Results}

The simulation results have been obtained by means of PSIM 7.0.5 [15]. TABLE I shows the values of the system parameters.

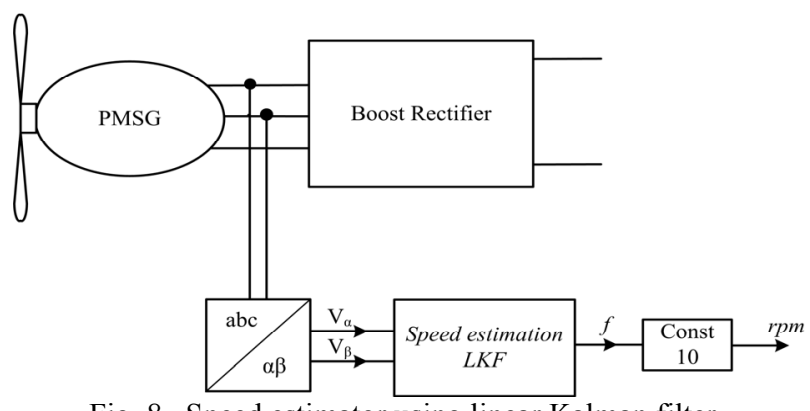

Fig. 8. Speed estimator using linear Kalman filter.

TABLE I. The values of the simulation.

\begin{tabular}{|l|c|}
\hline \multicolumn{1}{|c|}{ Characteristics } & Values \\
\hline Output voltage range of the generator $\left(\mathrm{V}_{\mathrm{ab}}\right)$ & $104-416 \mathrm{~V}_{\mathrm{rms}}$ \\
\hline Constant of the electromotive force $(\mathrm{K})$ & $6.63 \mathrm{~V}_{\mathrm{rms}} / \mathrm{rad} / \mathrm{s}$ \\
\hline Number of poles $\left(\mathrm{n}_{\mathrm{p}}\right)$ & 12 \\
\hline Speed Range of the generator $\left(\mathrm{n}_{\mathrm{m}}\right)$ & $150-600 \mathrm{rpm}$ \\
\hline $\begin{array}{l}\text { Inductance of one phase of the generator }\left(\mathrm{L}_{\mathrm{ga}}=\right. \\
\left.\mathrm{L}_{\mathrm{gb}}=\mathrm{L}_{\mathrm{gc}}=\mathrm{L}\right)\end{array}$ & $25 \mathrm{mH}$ \\
\hline $\begin{array}{l}\text { Resistance of one phase of the generator }\left(\mathrm{R}_{\mathrm{ga}}=\right. \\
\left.\mathrm{R}_{\mathrm{gb}}=\mathrm{R}_{\mathrm{gb}}=\mathrm{R}\right)\end{array}$ & $5 \Omega$ \\
\hline $\begin{array}{l}\text { Boost Inductance associated to each phase }\left(\mathrm{L}_{\mathrm{a},}\right. \\
\left.\mathrm{L}_{\mathrm{b}}, \mathrm{L}_{\mathrm{c}}\right)\end{array}$ & $375 \mu \mathrm{H}$ \\
\hline $\begin{array}{l}\text { Resistance in series associated to the Boost } \\
\text { inductor in each phase }\left(\mathrm{R}_{\mathrm{La}}, \mathrm{R}_{\mathrm{Lb}}, \mathrm{R}_{\mathrm{Lc}}\right)\end{array}$ & $37.5 \mathrm{~m} \Omega$. \\
\hline Sampling time $\left(\mathrm{T}_{\mathrm{s}}\right)$ & $2.2 \mu \mathrm{F}$ \\
\hline
\end{tabular}

Fig. 9 shows the response of each of the studied speed estimators. Note that the estimator using PLL, the estimator using the EKF by measuring the voltages of the output generator, and the estimator using the LKF properly follow the actual speed. However, the estimator using the currents and voltages in the rectifier and the estimator using EKF by the electromotive force, one match at certain speeds but not at all speeds. The problem is attributed to the components of the switching frequency and of harmonics that contain the currents and the voltages of the output generator, as shown in Fig. 2.
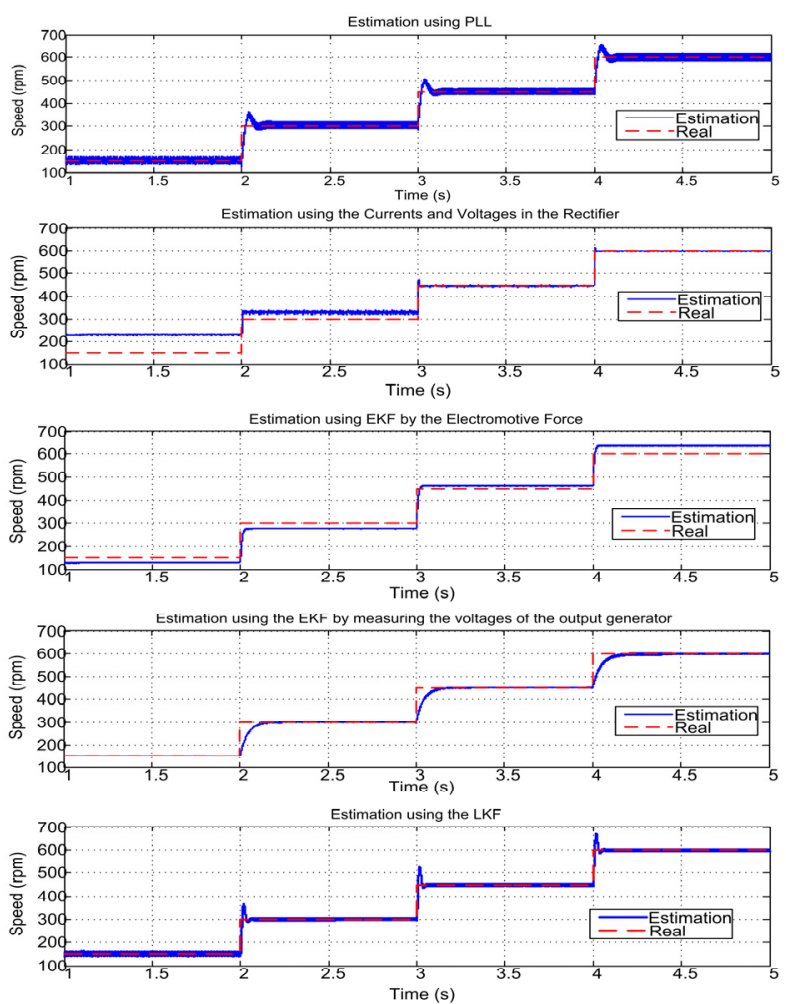

Fig. 9. The response of each of the speed estimators. 
Fig. 10 shows the estimation errors that follow the actual speed of the generator. The estimator using PLL has a maximum ripple of $\pm 16 \mathrm{rpm}$, the estimator using EKF measuring the voltages of the output generator has a maximum ripple of $\pm 4.5 \mathrm{rpm}$ and the estimator using $\mathrm{LKF}$ has a maximum ripple of $\pm 10 \mathrm{rpm}$. Fig. 10 also shows the filtering error of each of the estimators. They are used to obtain the response time with step of $150 \mathrm{rpm}$ in the generator speed. The estimator using PLL has a response time of $150 \mathrm{~ms}$, the estimator using EKF measuring the voltages of the generator output has a response time of $250 \mathrm{~ms}$ and the estimator using the LKF has a response time of $80 \mathrm{~ms}$.

\section{Conclusion}

From the results and the algorithms needed to implement each one of the estimators, it may be concluded that the appropriate for this application is the LKF, because it has better performance with regard to measurement noise. Besides, the LKF algorithm is less complex than the other that it has been studied. In the follow months, it will be built a wind turbine emulator to validate the PSIM simulations. Currently, Three-phase boost rectifier in DCM is operated with a control PCC.

\section{Acknowledgement}

The first author thanks the support of the Instituto Politécnico Nacional (IPN) and of the Comisión de Operación y Fomento de Actividades Académicas (COFAA) to finance his stay at the Universidad Politécnica de Valencia (UPV).
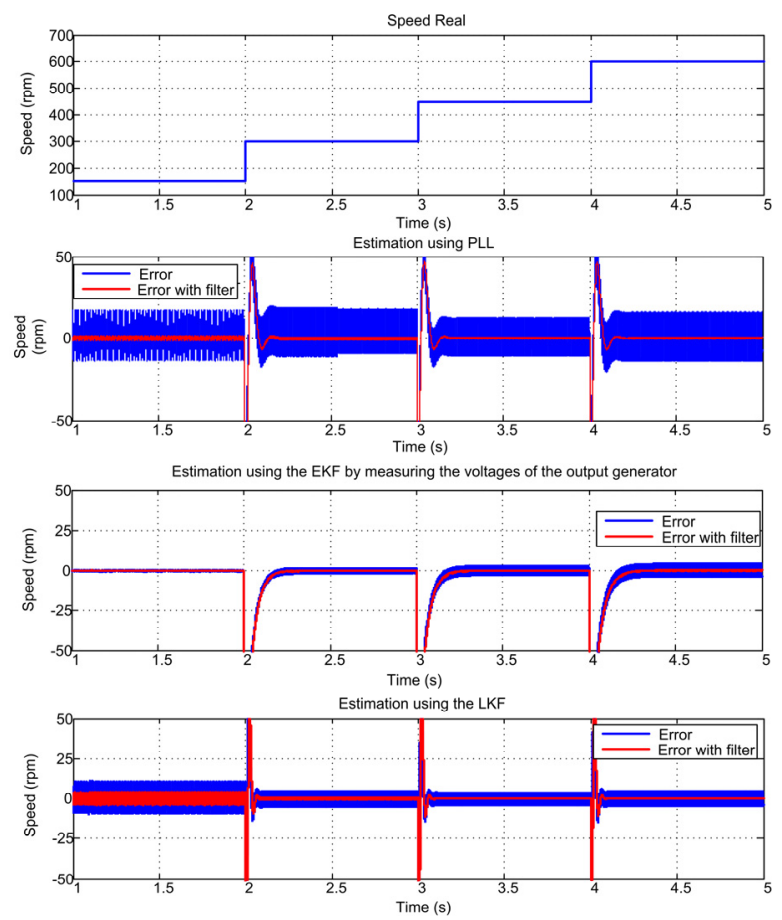

Fig. 10. The error in the speed estimators.

\section{References}

[1] Jamal A. Baroudi, Venkata Dinavahi, Andrew M. Knight, "A review of power converter topologies for wind generators", Renewable Energy 32, pp. 2369-2385, 2007.

[2] O. Carranza, E. Figueres, G. Garcera, L. G. Gonzalez, F. Gonzalez-Espin, "Peak Current Mode Control of a Boost Rectifier with Low Distortion of the Input Current for Wind Power Systems based on Permanent Magnet Synchronous Generators", 13th European Conference on Power Electronics and Applications, EPE '09. 8-10 Sept. 2009 pp. 1-10.

[3] A.M. Salamah, S.J. Finney, B.W. Williams, "Three-phase phase-lock loop for distorted utilities", IET Electric Power Applications, Vol. 1, Issue 6, Nov. 2007 pp. 937 $-945$

[4] P. Rodriguez, J. Pou, J. Bergas, J.I. Candela, R.P. Burgos, D. Boroyevich, Decoupled Double Synchronous Reference Frame PLL for Power Converters Control, IEEE Transactions on Power Electronics, Vol. 22, Issue 2, March 2007, pp. $584-592$.

[5] Mohan, Undeland, Robbins, Power Electronics, Converters, Applications and Desig, USA, John Wiley \& Sons, INC, 2003.

[6] S. Bolognani, R. Oboe, and M. Zigliotto, "Sensorless Full-Digital PMSM Drive With EKF Estimation of Speed and Rotor Position , " IEEE trans. on Industrial Electronics, February 1999, vol. 46, no.1, pp. 184-191

[7] Chan Tze-Fun, P. Borsje, Wang Weimin, "Application of Unscented Kalman filter to sensorless permanent-magnet synchronous motor drive", IEEE International Electric Machines and Drives Conference, IEMDC '09, 3-6 May 2009, pp. 631-638.

[8] L.G. González, E. Figueres, G. Garcerá, O. Carranza, "Maximum-power-point tracking with reduced mechanical stress applied to wind-energy-conversionsystems", Applied Energy, In Press, Corrected Proof, Available online 6 January 2010.

[9] Qiu, Wu Bin, H. Kojori, "Sensorless control of permanent magnet synchronous motor using extended Kalman filter", Conference on Electrical and Computer Engineering, 2004. Canadian, Vol. 3, pp 1557- 1562, 2-5 May 2004.

[10] Yin Ming, Li Gengyin, Zhou Ming, Zhao Chengyong, "Modeling of the Wind Turbine with a Permanent Magnet Synchronous Generator for Integration", IEEE Power Engineering Society General Meeting, 2007, 24-28 June 2007 pp. $1-6$.

[11] L.Harnefors, "Speed Estimation From Noisy Resolver Signal," Proceedings of the Sixth International Conference on Power Electronics and Variable Speed Drives, pp. 279-282, 1996;

[12] M.C. Huang, A.J. Moses, F. Anayi, X.G. Yao, "Linear Kalman filter (LKF) sensorless control for permanent magnet synchronous motor based on orthogonal output linear model", International Symposium on Power Electronics, Electrical Drives, Automation and Motion, 2006. SPEEDAM 2006. 23-26 May 2006, pp.1381 - 1386 S. Stasi, L.

[13] Liu Yong, Zhu Zi Qiang, D. Howe, "Instantaneous Torque Estimation in Sensorless Direct-TorqueControlled Brushless DC Motors", IEEE Transactions on Industry Applications, Vol. 42, Issue 5, Sept.-Oct. 2006, pp. $1275-1283$.

[14] Matlab 7.6, User's Guide (2008), MathWork Inc, February 2008.

[15] PSIM 7.0 User's Guide (2006), Powersim Inc., March 2006. 